\title{
Microwave Combustion and Sintering Without Isostatic Pressure
}

\author{
Topical Report \\ January 1998
}

\author{
By: \\ M. A. Ebadian
}

Work Performed Under Contract No.: DE-FG21-95EW55094

For

U.S. Department of Energy Office of Fossil Energy

Federal Energy Technology Center

P.O. Box 880

Morgantown, West Virginia 26507-0880

RECEIVED

OCT 201998

OSTI

By

Florida International University

Hemispheric Center for Environmental Technology (HCET)

Center for Engineering \& Applied Sciences

10555 West Flagler Street

EAS-2100

Miami, Florida 33174 


\section{Disclaimer}

This report was prepared as an account of work sponsored by an agency of the United States Government. Neither the United States Government nor any agency thereof, nor any of their employees, makes any warranty, express or implied, or assumes any legal liability or responsibility for the accuracy, completeness, or usefulness of any information, apparatus, product, or process disclosed, or represents that its use would not infringe privately owed rights. Reference herein to any specific commercial product, process, or service by trade name, trademark, manufacturer, or otherwise does not necessarily constitute or imply its endorsement, recommendation, or favoring by the United States Government or any agency thereof. The views and opinions of authors expressed herein do not necessarily state or reflect those of the United States Government or any agency thereof. 


\section{DISCLAIMER}

Portions of this document may be illegible electronic image products. Images are produced from the best available original document. 
This report is based on work supported be the U.S. Department of Energy, Office of Environmental Management, Office of Science and Technology's Decontamination and Decommissioning Focus Area, Morgantown Energy Technology Center. The Principal Investigator, the Florida International University Collaborator, and the students at Florida International University would like to thank Dr. Paul Hart for providing the opportunity to work on this project. 


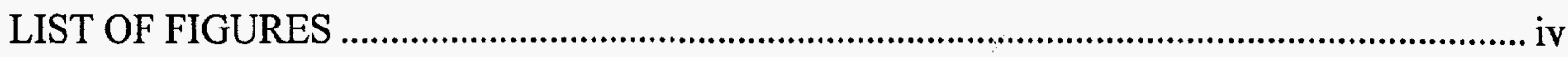

LIST OF TABLES

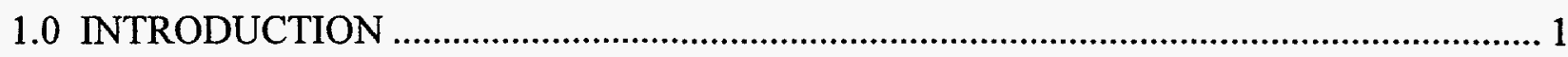

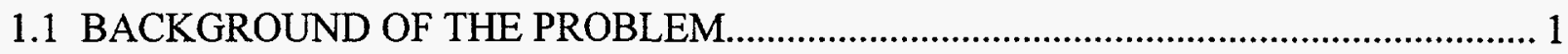

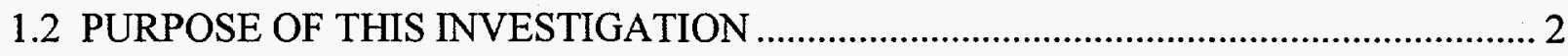

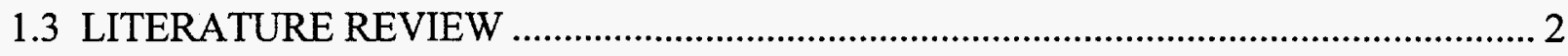

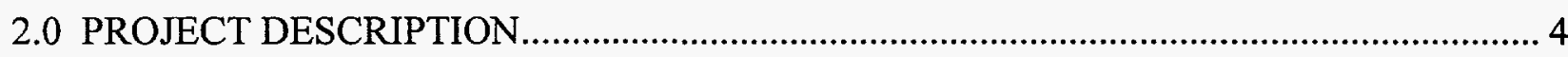

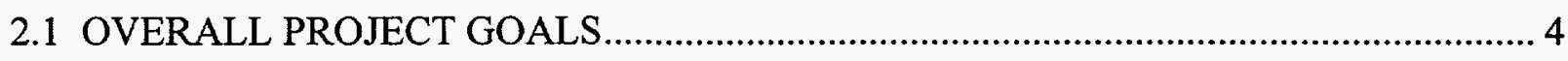

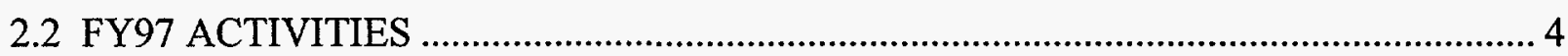

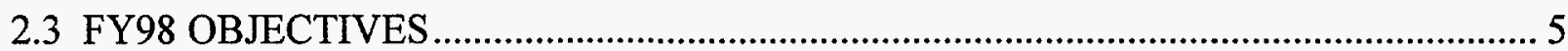

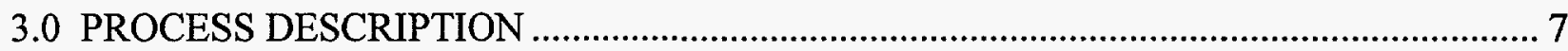

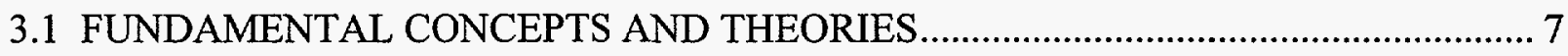

3.2 SAFETY AND REGULATORY CONCERNS ……....................................................... 9

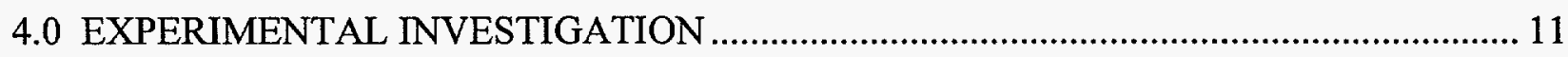

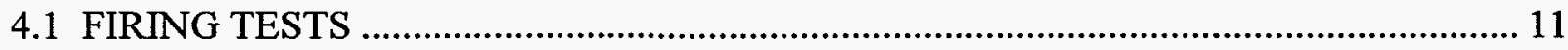

4.2 MEASUREMENT OF PHYSICAL PROPERTIES .......................................................... 11

4.3 ANALYSIS OF MINERALOGICAL COMPOSITION ………………………………..... 12

4.4 MEASUREMENT OF DIELECTRIC CONSTANTS ..................................................... 12

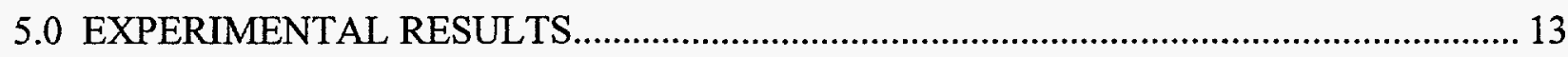

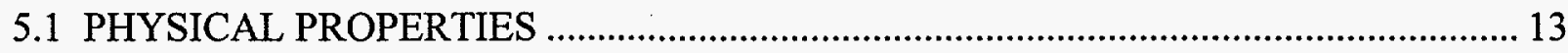

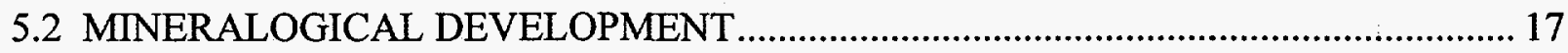

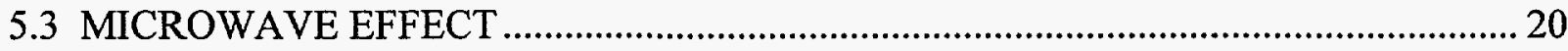

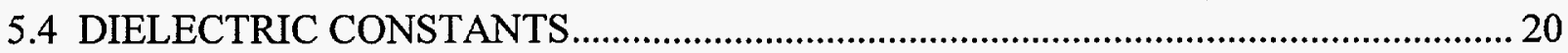

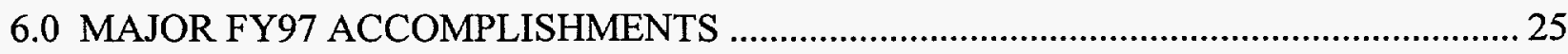

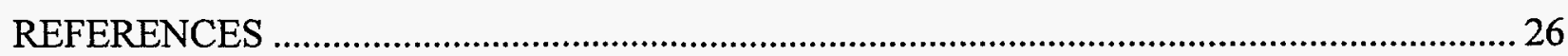




\section{LIST OF FIGURES}

Figure 1. A schematic flow-chart of the MCVI process ....................................................... 8

Figure 2. A schematic diagram of the MCVI reactor configuration.......................................... 9

Figure 3. Weight loss upon sintering of bauxite materials under an air atmosphere with the duration of one hour .................................................................................. 13

Figure 4. Weight loss upon sintering of bauxite materials for four hours in an air atmosphere.

Figure 5. Volume contraction upon sintering of bauxite materials under an air atmosphere with the duration of one hour. 14

Figure 6. Volume contraction upon sintering of bauxite materials for four hours in an air atmosphere.

Figure 7. Specific gravity upon sintering of bauxite materialsfor one hour in an air atmosphere.

Figure 8. Specific gravity upon sintering of bauxite materials for four hours in an air atmosphere

Figure 9. Corundum developed in the extrudates fired conventionally for one hour. 17

Figure 10. Corundum developed in the extrudates fired conventionally for four hours. 18

Figure 11. Mullite developed in the extrudates fired conventionally for one hour .................... 18

Figure 12. Mullite developed in the extrudates fired conventionally for four hours .................. 19

Figure 13. Dielectric constant of beneficiated bauxite at different temperatures ........................ 21

Figure 14. Dielectric constant of capping material at different temperatures.............................. 21

Figure 15. Dielectric constant of tailing pond material at different temperatures...................... 22

Figure 16. Dielectric constant of traditional bauxite at different temperatures ........................... 22

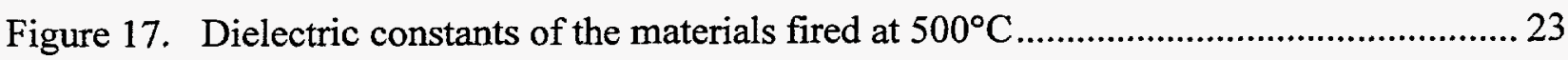

Figure 18. Dielectric constants of the materials fired at $1100^{\circ} \mathrm{C}$.............................................. 23

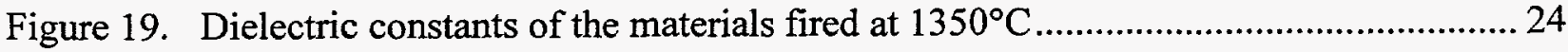

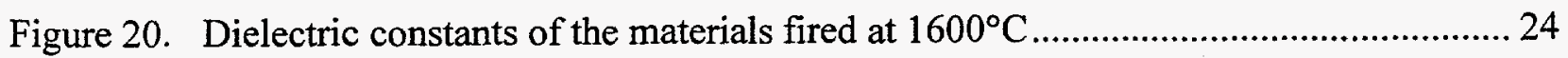


Table 1. Weight loss of extrudates fired in a variable frequency microwave furnace at $1350^{\circ} \mathrm{C}$ for 30 minutes

Table 2. Volume contraction of extrudates fired in a variable frequency microwave furnace at $1350^{\circ} \mathrm{C}$ for 30 minutes

Table 3. Mineralogical development in extrudates fired in a variable frequency microwave furnace (\%)

Table 4. Processing time and electrical energy requirement for the microwave firing and conventional firing... 


\subsection{INTRODUCTION}

In recent years interest has grown rapidly in the application of microwave energy to the processing of ceramics, composites, polymers, and other materials. Advances in the understanding of microwave/materials interactions will facilitate the production of new ceramic materials with superior mechanical properties. One application of particular interest is the use of microwave energy for the mobilization of uranium for subsequent redeposition.

This investigation is being conducted in three phases, the final phase of which will be devoted to the mobilization and deposition of uranium species using microwave assisted chemical vapor infiltration. Phase II (FY97) consisted of fundamental research on the conventional sintering and microwave sintering of various mixes of ceramics and dielectric constant determination.

Phase III (FY98) will focus on the microwave assisted chemical vapor infiltration tests for mobilization and redeposition of radioactive species in the mixed sludge waste. Uranium hexachloride and uranium (IV) borohydride are volatile compounds for which the chemical vapor infiltration procedure might be developed for the separation of uranium. Microwave heating characterized by an inverse temperature profile within a preformed ceramic matrix will be utilized for CVI using a carrier gas. Matrix deposition is expected to commence from the inside of the sample where the highest temperature is present. The preform matrix materials, which include aluminosilicate based ceramics and silicon carbide based ceramics, are all amenable to extreme volume reduction, densification, and vitrification. Important parameters of microwave sintering such as frequency, power requirement, soaking temperature, and holding time will be investigated to optimize process conditions for the volatilization of uranyl species using a reactive carrier gas in a microwave chamber.

\subsection{BACKGROUND OF THE PROBLEM}

Growing evidence supports the use of microwave energy in certain industrial processes and for continued research and development for using it in many other materials processing applications, such as radioactive waste disposal. In contrast to conventional furnaces, the material to be processed in a microwave furnace interacts with the "cold" microwaves instead of radiant heat.

In the application of mixed waste disposal, conventional heating is inferior to microwave heating. Conventional joule heating requires electrodes in direct contact with the mixed waste. Electrode corrosion can limit the service life of these smelters. In microwave treatment, microwave energy is absorbed by a large class of waste materials commonly found in many lowlevel waste streams such as fabrics, rubber, concrete, metal powders, oxides, nitrides, sulfates, nonmetallic filtering media, water, carbon, and glass. Because microwave energy is absorbed directly, it has the considerable advantage of much higher efficiency and faster temperature control compared to conventional radiant heating. Microwave power can be transmitted through wave guides from generators that can be located safely outside a radioactive processing area where routine system maintenance can be easily performed. Microwave heating is extremely flexible in that a wide range of processing temperatures are available in a single system. Microwave disposal systems can be designed to be small enough to be mobilized for on-site treatment of radioactive wastes. Heating profiles can be custom-tailored for each application by exciting the appropriate microwave field configuration or "mode," choosing the proper heating 
frequency and material geometry, and understanding how the microwave penetration depth is controlled by temperature and material composition of the waste form.

Microwave assisted chemical vapor infiltration (MCVI), an innovative technique to fabricate fiber reinforced ceramic composites, has been proposed as a technique for treating radioactive waste. Uranium hexachloride and uranium (IV) borohydride are volatile compounds for which the chemical vapor infiltration procedure might be developed for the separation of uranium. The radioactive species in mixed waste, after mixing with a reactant gas, produces volatile compounds in a microwave cavity. These compounds are transported by a carrier/reactant gas to a react tube, where the MCVI will take place. The volatilized uranyl species that is deposited in the ceramic matrix will be vitrified in-situ.

\subsection{PURPOSE OF THIS INVESTIGATION}

This project is devoted to the development of an innovative technique for the disposal of mixed waste using microwave energy. Because most uranium and plutonium components as well as most fission products have dielectric properties that allow excellent microwave and high frequency energy coupling, dielectric heating has the potential for application in many processes for treating hazardous wastes. This technology, whether used on its own or as hybrid in conjunction with a conventional process, has positive features such as energy efficiency, increased throughput, volume reduction, reduction of disposal and transportation cost and provides a technique not feasible by conventional means. The hazardous waste will be converted into a dense, stable and vitrified form, so that it may qualify for eventual off-site disposal. If successful, this program will lead to major cost savings for the DOE system.

\subsection{LITERATURE REVIEW}

Chemical vapor infiltration (CVI) is an attractive technique for introducing matrix materials into fibrous reinforcements as it minimizes stress during processing (Day et al., 1994). Also, when compared to hot pressing, relatively low temperatures are used which limits unwanted chemical attack on the reinforcement. Difficulties associated with CVI processing using conventional heating are preferential deposition in the substrate's outer regions leading to pore blockage; long processing time; non-uniform composite density; high residual porosity; and limitations on substrate geometry (Devlin et al.,1993).

The use of microwave energy in the CVI processing has received recent attention due to the volumetric heating and the resultant inverse temperature profile (Devlin et al.,1993). With the internal region of the substrate hot, the cool reactant gases penetrate inwardly before the onset of the deposition reaction. It should be noted that the inverse temperature gradients could also be established by "seeding" the center (or one side) of the preform with a material which readily absorbs microwave energy. The following advantages of MCVI over the conventional CVI have been well demonstrated by several researchers (Devlin et al., 1993; Spotz et al., 1993; Day et al., 1994; Skamser et al., 1994): 1) relatively short processing time; 2) no limitations on the preform geometry; 3) products with spatially uniform and high density; deposition from the inside-out.

MCVI has been documented in the fabrication of $\mathrm{Al}_{2} \mathrm{O}_{3}$ fiber $/ \mathrm{Al}_{2} \mathrm{O}_{3}$ matrix composites (Skamser et al., 1994) and the SiC fiber/SiC matrix composites (Deepak and Evans, 1993; Day et al., 1994). Infiltration of $\mathrm{Si}_{3} \mathrm{~N}_{4}$ in Nicalon ${ }^{\mathrm{TM}}$ cloth (Devlin et al., 1993), $\mathrm{SiC}$ and $\mathrm{ZrO}_{2}$ into reticulated 
$\mathrm{SiC}$ foam, Nicalon ${ }^{\mathrm{TM}}$ cloth and $\mathrm{ZrO}_{2}$ based porous fiber boards (Yin et al., 1997) were also experimentally demonstrated. Experiments conducted and described in these reports required the application of microwave radiation at a fixed frequency. 


\subsection{PROJECT DESCRIPTION}

This project involves the following phases of investigations of the utilization of microwave energy: 1) sintering of aluminsilicate materials, 2) sintering of matrix materials for chemical vapor infiltration of radioactive materials, 3) investigation of microwave-assisted, chemical vapor infiltration techniques.

\subsection{OVERALL PROJECT GOALS}

Based on the results of investigations on the microwave-assisted, chemical vapor infiltration tests for the surrogates of waste, an innovative technique involving microwave energy may be developed for decontamination and decommissioning of radioactive waste.

In FY97, fundamental research was conducted on the microwave sintering of various aluminosilicate materials. The mineralogical development of these materials during microwave firing has been evaluated. The changes of the dielectric constant with the temperature (up to $200^{\circ} \mathrm{C}$ ) of these materials were determined. The process of chemical vapor infiltration experiments has been outlined.

The overall project goals for FY98 are:

- To demonstrate the conventional chemical vapor infiltration technology with surrogates of radioactive species. A conventional furnace will be modified to meet this objective.

- To develop the microwave-assisted, chemical vapor infiltration technology for the volatilization, mobilization and deposition of the surrogate species in ceramic matrices.

- To apply the microwave-assisted, chemical vapor infiltration technology for the decontamination and decommissioning of the high-level waste.

It is expected that the results of this investigation will be useful to the U.S. Department of Energy (DOE) for application in a microwave-assisted, chemical vapor infiltration process. This technology can be used for the in-situ remediation of hazardous waste or as a hybrid microwave technology.

\subsection{FY97 ACTIVITIES}

During FY97, extrudates of various compositions of bauxite materials were fired in a conventional high temperature box furnace under air atmosphere and in a variable frequency microwave furnace. The weight loss, volume contraction and true specific gravity, as well as the mineralogical composition were determined. The dielectric constants of the fired extrudates has also been determined with a Hewlett Packard Network Analyzer.

FY97 activities included:

- Determination of the composition of the starting materials by chemical analysis.

- Firing the four types of bauxite extrudates - raw bauxite, beneficiated bauxite, tailing pond material and capping material-under air atmosphere in a conventional high temperature 
furnace at $1350^{\circ}, 1450^{\circ}, 1550^{\circ}$ and $1600^{\circ} \mathrm{C}$ for four hours and at $1450^{\circ}, 1550^{\circ}, 1650^{\circ}$ and $1700^{\circ}$ for one hour.

- Firing the four types of bauxite extrudates in a $1.2 \mathrm{KW}$ variable frequency microwave furnace (VFMF) at a frequency of 5.5-5.75 Ghz with a sweeping rate of three seconds at $1100^{\circ} \mathrm{C}$ for one minute and at $1350^{\circ}$ and $1550^{\circ} \mathrm{C}$ for 30 minutes.

- Determination of the mineralogical composition of the fired products by powder X-ray diffraction (XRD).

- In-situ analysis of the changes of the dielectric constant of the four types of materials with the temperature up to $200^{\circ} \mathrm{C}$.

- Determination of the dielectric constant of the extrudates that were fired at $500^{\circ}, 800^{\circ}$, $1100^{\circ}, 1350^{\circ}$ and $1600^{\circ} \mathrm{C}$.

- Attendance at the First World Congress on Microwave Processing in Orlando, Florida on Jan. 5-9, 1997 and presentation of the project in the 32nd Microwave Power symposium on July 14-16, 1997 in Ottawa, Canada.

- Preparation of technical papers for presentation at the following conferences: The 32nd Microwave Power Symposium (July 14-16, 1997 in Ottawa, Canada) and the Second International Congress on Metallurgy and Materials Technology (October 12-17, 1997 in Sao Paulo, Brazil). In addition, a refereed journal paper derived from this project has been accepted by the Journal of Microwave \& Electromagnetic Energy.

- A literature search to determine: 1) A suitable surrogate for mixed waste, 2) A processing flow chart for the chemical vapor infiltration (CVI) and microwave assisted chemical vapor infiltration (MCVI) processes, 3) Instrumentation and supplies for conducting preliminary CVI experiments, 4) Suitable carrier gas/reaction gas mixtures, and 4) Types of ceramic matrix preform.

\subsection{FY98 OBJECTIVES}

During FY98, investigations will focus on the following:

- Conventional Vitrification of the Mixed Waste Surrogate. Preliminary vitrification tests will be conducted on the conventional high temperature furnace. The volume reduction, heating temperature, time required for vitrification and the thermal and chemical stability of the products will be evaluated. This information is essential for assessing the efficiency of the CVI and MCVI processes.

- Conventional Chemical Vapor Infiltration for Waste Disposal. CVI experiments will be conducted using a conventional furnace. The experimental set up to demonstrate the CVI process for treatment of mixed waste will be accomplished at the Hemispheric Center for Environmental Technology (HCET). A surrogate of the radioactive species in the mixed waste will be volatilized and mobilized by a carrier gas and then deposited in a ceramic matrix. The deposited products will be vitrified in the conventional high temperature furnace. 
- Microwave Assisted Chemical Vapor Infiltration for Waste Disposal. Microwave energy will be utilized in the CVI processing to extract and deposit the radioactive species in the mixed waste. The MCVI system will consist of a microwave source and cavity, a gas delivery system, a quartz reactor tube with exhaust plumbing and vacuum connection, pressure control and a scrubbing unit. The reacting/carrier gas (1) will react with the radioactive species present in the mixed waste in the volatilization chamber to produce volatile compounds. Reacting/carrier gas (2) will react with the volatile compounds, and infiltration deposition will proceed within the preform ceramic matrix located inside of the microwave cavity. The products will be vitrified in-situ. 


\subsection{PROCESS DESCRIPTION}

Although it is still in an early stage of development, the use of microwave energy to process a wide variety of ceramic materials offers many new and exciting opportunities. There are several reasons for the growing interest in microwave processing versus conventional processing methods. These include the potential for significant reductions in manufacturing costs due to energy savings and shorter processing times, improved product uniformity and yields, improved or unique microstructures and properties, and the synthesis of new materials. In the case of MCVI, this would overcome the main problems encountered in conventional CVI where preferential deposition in the substrate's outer regions leads to pore blockage, long processing time, non-uniform composite density, high residual porosity, and limitations on substrate geometry. The present research attempts to apply the MCVI technology to mobilize and redeposit the radioactive species in the mixed waste.

Uranium hexachloride and uranium (IV) borohydride are volatile compounds for which the chemical vapor infiltration procedure might be developed for the separation of uranium. Microwave energy will be utilized for vaporization of the uranium species using a carrier gas. The gas delivers the uranium volatile compounds to the ceramic matrix preforms positioned in a quartz tube, which is heated by microwave energy. Matrix deposition is expected to commence from the inside of the sample where the highest temperature is present. The matrix material will include alumina based ceramics and alumino-silicates, as well as SiC. These materials are all amenable to extreme volume reduction, densification and vetrification. The preforms will be weighted before and after each infiltration run to determine the deposition rate. The various parameters in microwave sintering such as frequency, power requirement, soaking temperature, and holding time will be investigated to determine the optional conditions for the volatilization of uranyl species using a reactive carrier gas in a microwave chamber. The volatilized uranyl species that is deposited in the ceramic matrix will be vitrified in-situ. Thus, the radioactive species in the mixed wastes are separated and vitrified and ready to be disposed.

\subsection{FUNDAMENTAL CONCEPTS AND THEORIES}

Based upon the literature search conducted, a flow chart has been developed for the microwave assisted chemical vapor infiltration (MCVI) process for the treatment and decontamination of mixed radioactive waste (see Figure 1). As shown in the following charts, the MCVI system consists of a microwave source and cavity, a gas delivery system, a quartz reactor tube with exhaust plumbing and vacuum connection, pressure control and a scrubbing unit. The reacting/carrier gas 1 will react with the radioactive species present in the mixed waste in the volatilization chamber to produce volatile compounds. Reacting/carrier gas 2 will react with the volatile compounds, and infiltration deposition will proceed within the preform located inside of the microwave cavity. 


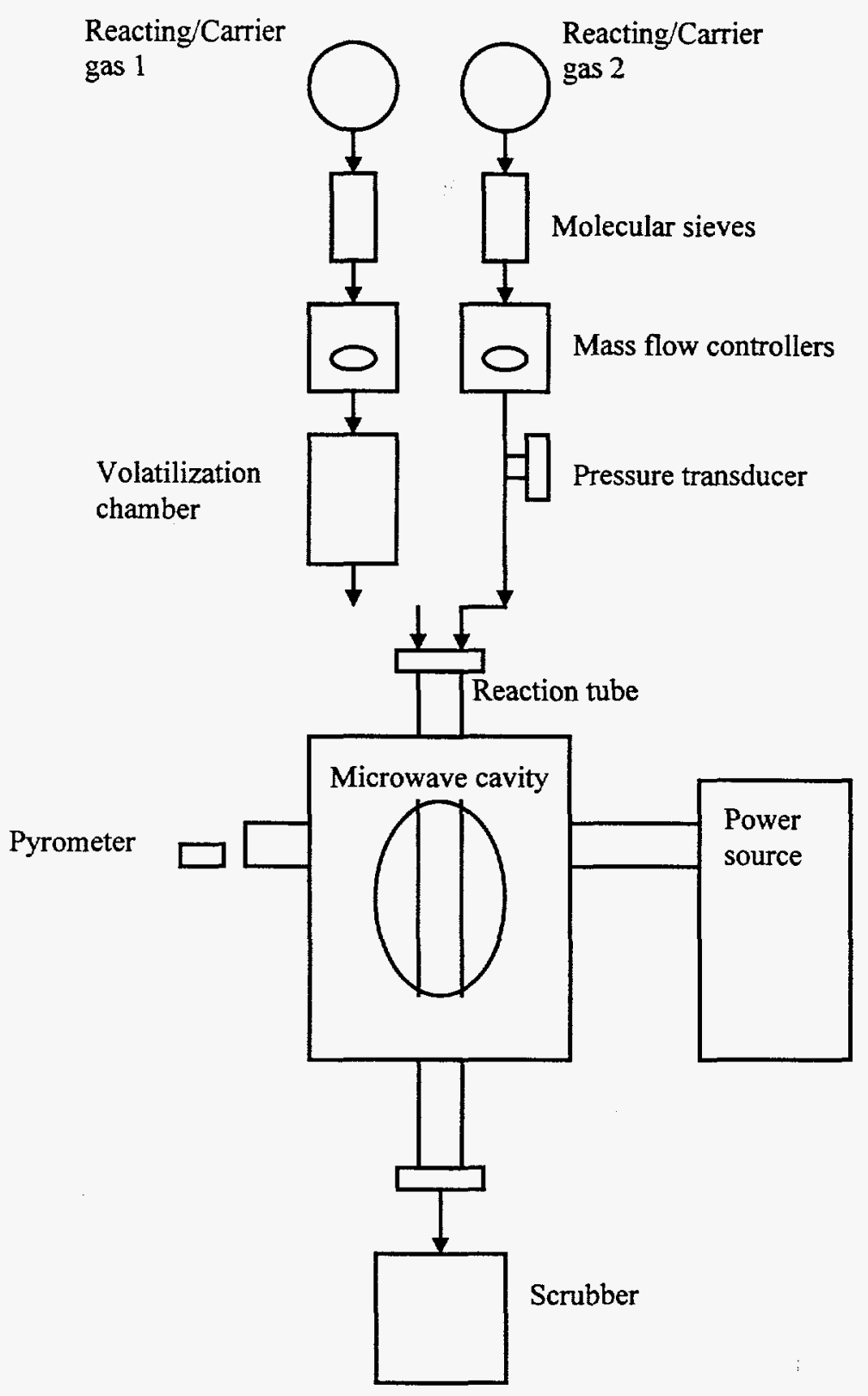

Figure 1. A Schematic flow-chart of the MCVI Process.

A schematic diagram of the MCVI reactor is shown in Figure 2. It will consist of a cylindrical microwave cavity through which a quartz reactor tube is inserted. A ceramic matrix preform will be loaded co-axially within the quartz tube. Since the heating configuration produces primarily radial temperature gradients, deposition is expected to commence at the preform axis and grow outwards. 


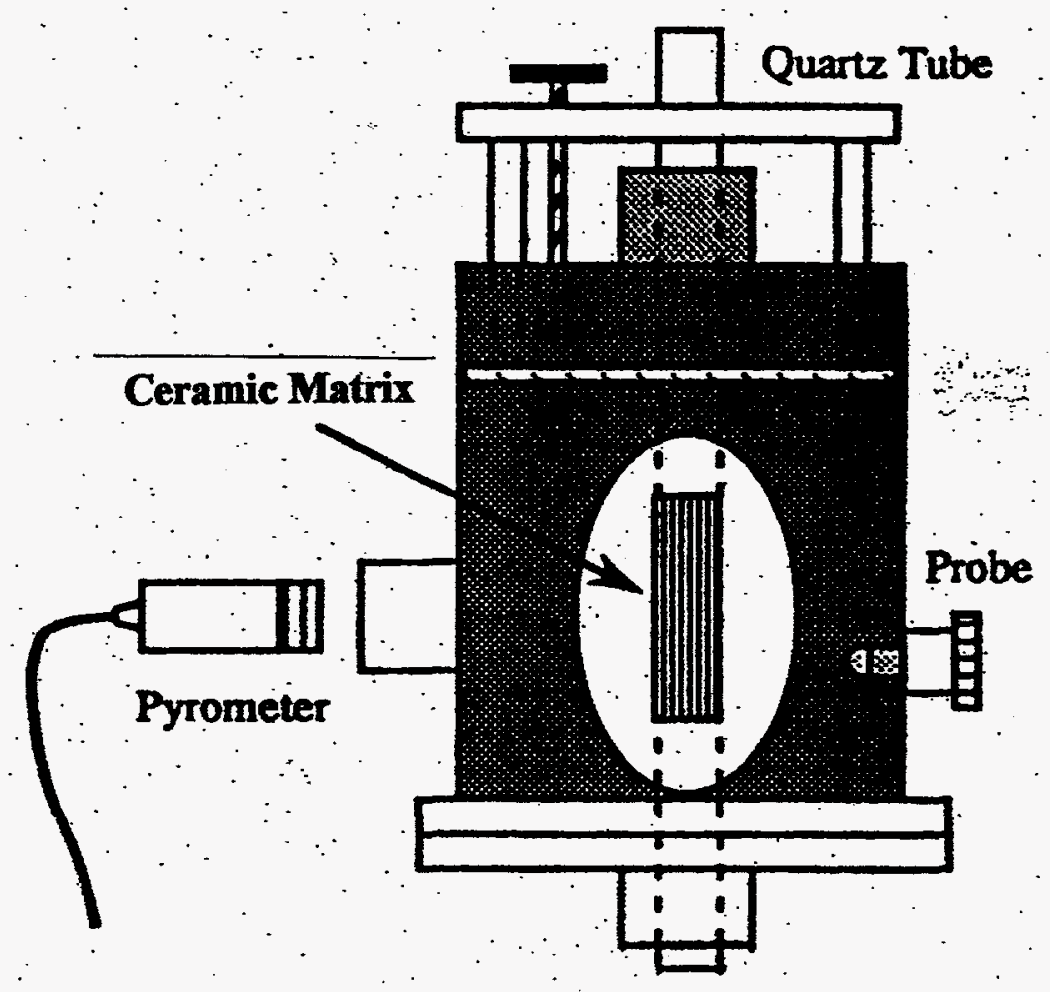

Figure 2. A Schematic Diagram of the MCVI reactor configuration.

\subsection{SAFETY AND REGULATORY CONCERNS}

The U. S. Department of Energy (DOE) has numerous regulatory requirements that must be followed by any DOE operation or contractor working at a DOE site in the United States. Since the Microwave Project involves radioactive wastes, the following regulations apply.

- DOE Order 5400.5, Radiation Protection of the Public and the Environment. This order constitutes a list of standards and requirements that DOE and its Contractors must abide by to operate the facility while protecting the public, work crews, and the environment against unnecessary risk from radiation.

- DOE Order 1332.1, Uniform Reporting System. This order applies to any operation related to the DOE. It establishes a uniform reporting system for contracts, loans, and loan guarantees and provides instructions, forms, and procedures for effective management.

- The U. S. Environmental Protection Agency (EPA) was established to reduce and control pollution by setting standards and enforcing regulatory policy. The regulatory requirements that must be followed include the Clean Air Act of 1970 (CAA), the Clean Water Act of 1977 (CWA), the Safe Drinking Water Act of 1974 (SDWA), and the Resource Conservation and Recovery Act (RCRA). Other laws that apply to hazardous waste include the Toxic Substances Control Act of 1976 (TSCA) and the Comprehensive Environmental Response, 
Compensation, and Liability Act (CERDLA), which addresses the cleanup of hazardous waste contamination from previous operations.

Lambda Technologies is providing a Microwave Leak Detector (MLD) to monitor any possible microwave leakage. The MLD will be interfaced with an interlock circuitry, which will immediately shutdown the unit if hazardous levels of microwave energy are detected.

The microwave furnace will be used in a heavily ventilated laboratory equipped with HEPAfiltered exhaust fume hoods. This will reduce the level of metal vapor in the laboratory as well as that of the exhaust fumes released into the atmosphere. 


\subsection{EXPERIMENTAL INVESTIGATION}

Experimental work completed in FY97 included the firing of four types of bauxite materials under air atmosphere in a conventional high temperature furnace and in a variable frequency microwave furnace. The weight loss, volume contraction, true specific gravity, as well as the mineralogical composition of the fired products were determined. The dielectric constants of the materials at various temperatures were also analyzed using a Hewlett-Packard Network Analyzer.

\subsection{FIRING TESTS}

Bauxite extrudates have been fired at $1450^{\circ}, 1550^{\circ}, 1650^{\circ}$, and $1700^{\circ} \mathrm{C}$ for one hour under an air atmosphere. Extrudates were also fired for a duration of four hours at $1350^{\circ}, 1450^{\circ}, 1550^{\circ}$ and $1600^{\circ} \mathrm{C}$ in an air atmosphere. Two conventional furnaces were utilized to conduct the firing. Pellets were preheated to about $800^{\circ} \mathrm{C}$ in the low temperature furnace and rapidly transferred to the high temperature furnace. The drop in the temperature was estimated to be less than $20^{\circ} \mathrm{C}$ during the transfer. The pellets were then heated at a rate of $5^{\circ} \mathrm{C} / \mathrm{min}$ to the expected temperatures in the conventional high temperature box furnace and held at the required temperature. These pellets were then allowed to cool to room temperature. In order to measure the physical and mineralogical properties of the sintered specimens, 16 batches of firing tests were conducted.

Microwave firing of bauxite extrudates was conducted in a $1.2 \mathrm{Kw}$ variable frequency microwave furnace (VFMF) at a frequency of $5.5-5.75 \mathrm{Ghz}$ with a sweeping rate of three seconds at Lambda Technologies, Inc.. Three firing regimes were adopted with the microwave furnace. The first regime involved heating the extrudates to $1100^{\circ} \mathrm{C}$ and maintaining that temperature for one minute. The other two regimes involved heating the extrudates up to $1350^{\circ} \mathrm{C}$ and $1550^{\circ} \mathrm{C}$ and maintaining that temperature for 30 minutes respectively. These tests revealed that with hybrid heating using silicon carbide as a susceptor only 20 minutes were required to achieve a firing temperature. The fired extrudates were found to be void of visible cracks.

\subsection{MEASUREMENT OF PHYSICAL PROPERTIES}

The weight loss, volume contraction and true specific gravity of the fired extrudates were measured. The weight loss was determined by the difference of the sample before and after firing. The dimension of each sample (radius and length) was measured prior to and proceeding the firing. The volume contraction was then estimated. To determine the true specific gravity, the fired samples were ground to a fine powder so that the individual particles were too small to contain pores. The true specific gravity of the powder was determined by means of a specific gravity bottle (a pycnometer). 


\subsection{ANALYSIS OF MINERALOGICAL COMPOSITION}

The mineralogical compositions of the fired extrudates were analyzed using a powder X-ray diffractometer with internal standard technique. Commercial micron powders of mullite, corundum, and cristobalite were used as the reference materials. Calcium fluoride was applied as the internal standard material. The internal standard material was mixed with the powders of the fired extrudates in an agate motor. The powders were covered with 10 milliliters of ethyl ether as the mixing solvent. The slug was stirred with a pestle until the liquid evaporated. Stirring considerably increases the degree of mixing. The mixture was exposed under X-ray and the relative contents of mullite, corundum, and cristobalite were calculated according to the diffraction peaks.

\subsection{MEASUREMENT OF DIELECTRIC CONSTANTS}

In-situ measurement of the dielectric constants for various bauxite materials was taken using a Hewlett Packard Network Analyzer along with a dielectric probe. In order to obtain the readings, the four samples (raw bauxite, beneficiated bauxite, tailing pond material and capping material) were heated up to $200^{\circ} \mathrm{C}$ and then the measurements were taken. A thermocouple was used to monitor the temperature of the sample while the readings were taken. Three readings at three distinct temperatures were taken for each of the four samples. This gives us a total of 12 curves to compare with each other. In order to avoid rapid cooling of the sample, the samples were wrapped in an insulating foam.

Ex-situ measurement of the dielectric constants for the extrudates fired at various temperatures was also taken. Extrudates were heated up to $500^{\circ} \mathrm{C}, 800^{\circ} \mathrm{C}, 1100^{\circ} \mathrm{C}, 1350^{\circ} \mathrm{C}$, and $1600^{\circ} \mathrm{C}$ respectively and held at those temperatures for one hour and then cooled down to the ambient temperature. The measurements were taken at ambient temperature, and three readings were taken for each of the four samples. A total of 20 curves were generated for comparison of dielectric properties as a function of firing temperature and frequency. 


\subsection{EXPERIMENTAL RESULTS}

The results of the experiments described in the previous chapter are reported in the following sections.

\subsection{PHYSICAL PROPERTIES}

The weight loss of the fired extrudates was shown in Figures 3 and 4 and Table 1.

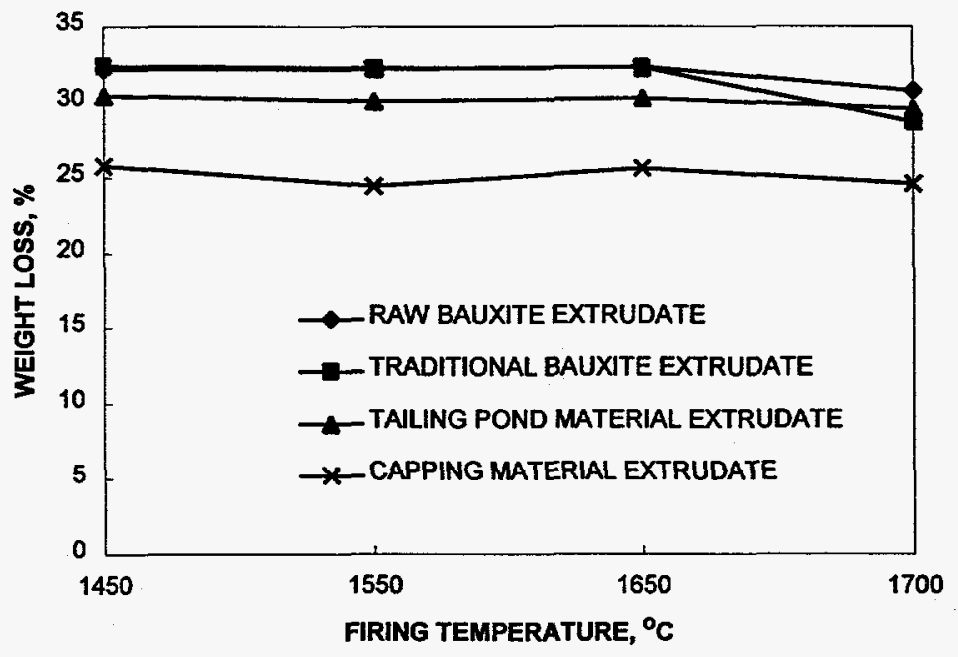

Figure 3. Weight loss upon sintering of bauxite materials under an air atmosphere with the duration of one hour.

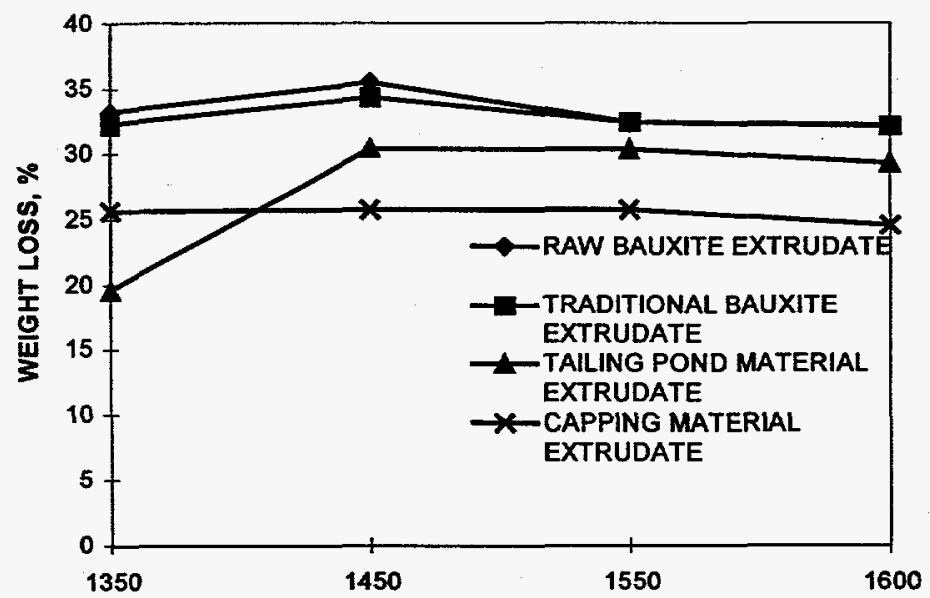

FIRING TEMPERATURE, ${ }^{\circ} \mathrm{C}$

Figure 4. Weight loss upon sintering of bauxite materials for four hours in an air atmosphere. 
Table 1.

Weight loss of extrudates fired in a variable frequency microwave furnace at $1350^{\circ} \mathrm{C}$ for 30 minutes

\begin{tabular}{|l|c|}
\hline & Weight loss (\%) \\
\hline Raw bauxite & 32.2 \\
\hline Beneficiated bauxite & 32.4 \\
\hline Tailing pond material & 30.4 \\
\hline Capping material & 25.8 \\
\hline
\end{tabular}

The volume contractions of the fired extrudates were shown in Figures 5 and 6 and Table 2.

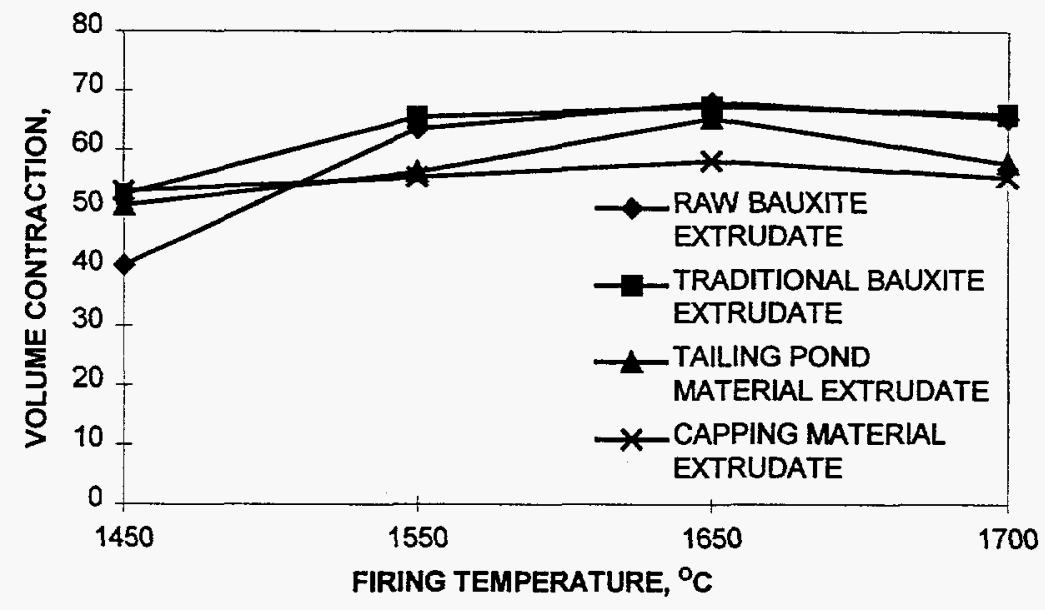

Figure 5. Volume contraction upon sintering of bauxite materials under an air atmosphere with the duration of one hour. 


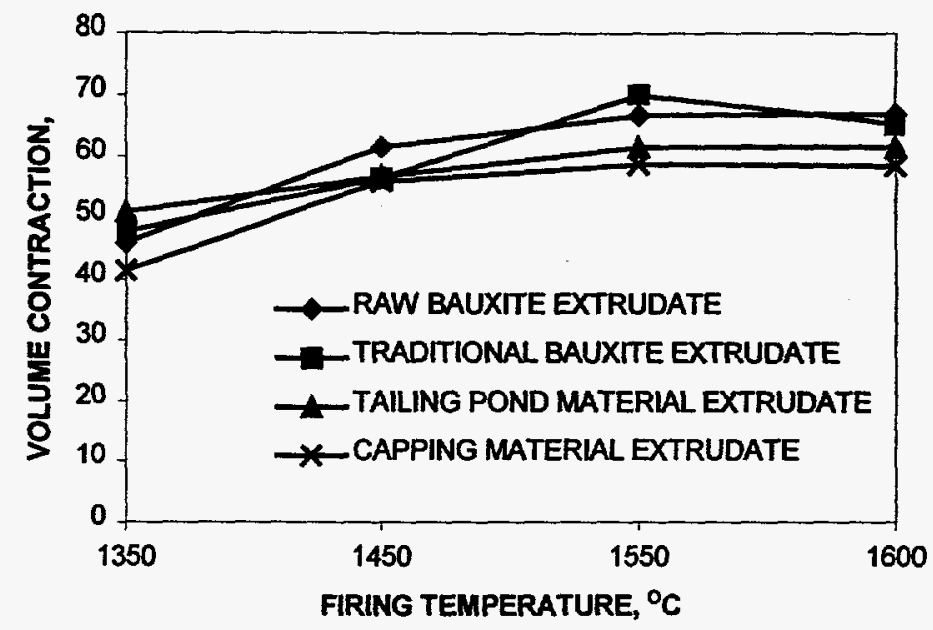

Figure 6. Volume contraction upon sintering of bauxite materials for four hours in an air atmosphere.

Table 2.

Volume contraction of extrudates fired in a variable frequency microwave furnace at $1350^{\circ} \mathrm{C}$ for 30 minutes

\begin{tabular}{|l|c|}
\hline & Volume contraction (\%) \\
\hline Raw bauxite & 39.0 \\
\hline Beneficiated bauxite & 41.1 \\
\hline Tailing pond material & 41.3 \\
\hline Capping material & 32.8 \\
\hline
\end{tabular}

The specific gravity of the fired extrudates is shown in Figures 7 and 8. 


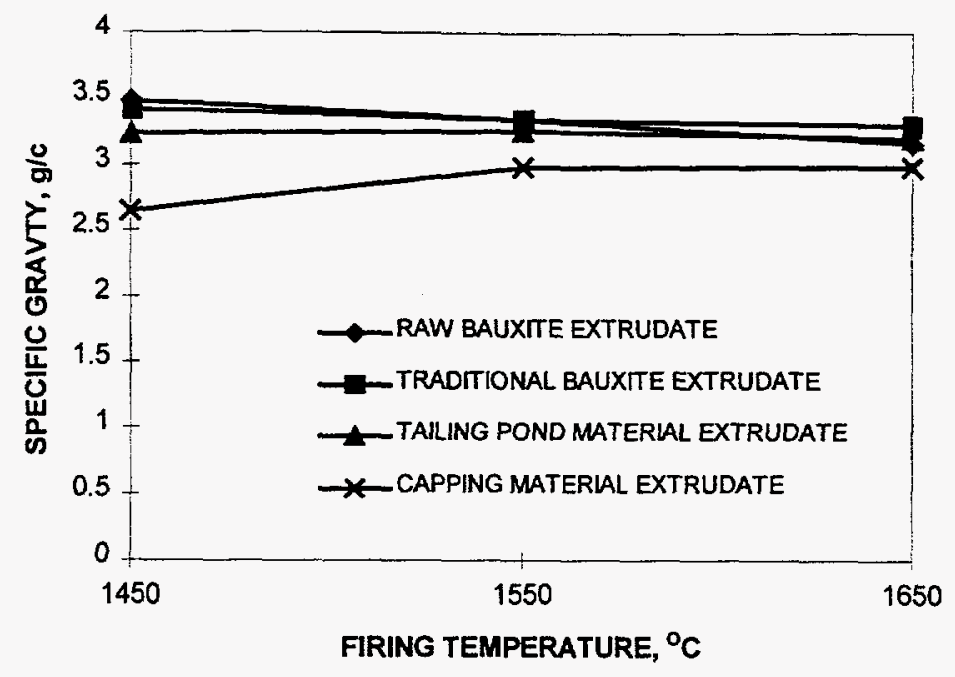

Figure 7. Specific gravity upon sintering of bauxite materials for one hour in an air atmosphere.

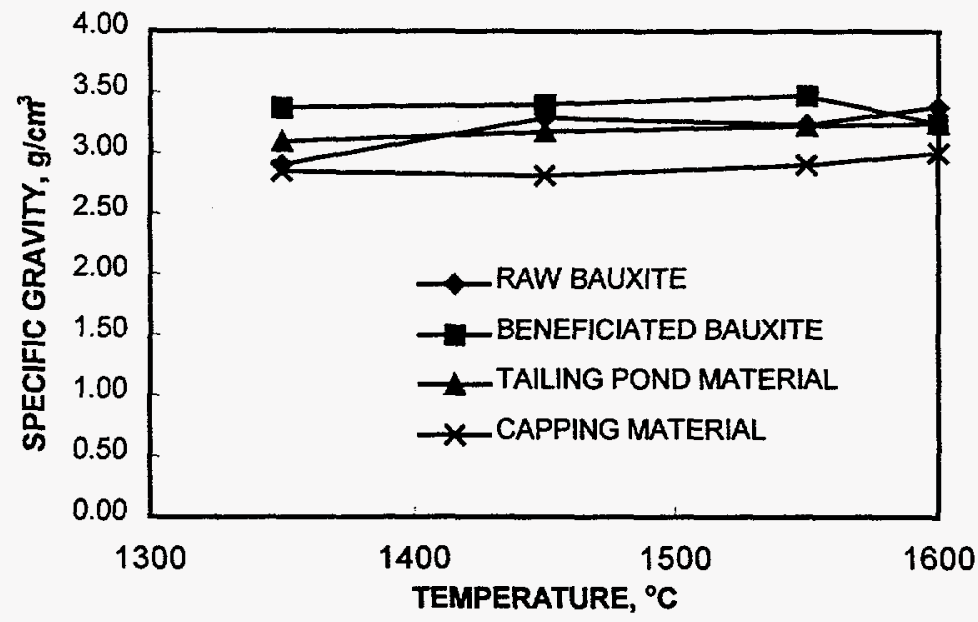

Figure 8. Specific gravity upon sintering of bauxite materials for four hours in an air atmosphere.

Considerable weight loss and volume contraction occurred during the firing of extrudates. Figures 3 and 4 show that the weight loss of beneficiated bauxite $(\approx 32.1 \%)$ was greater than that of the capping material $(\approx 25.5 \%)$. The weight loss for each type of material was independent of the type of furnace used (microwave or conventional) as well as the processing parameters (temperature and time). Figures 5 and 6 show that the volume contraction generally increased with increasing firing temperature. At the temperatures of $1550^{\circ} \mathrm{C}$ and above, beneficiated bauxite experienced greater volume contraction (up to $67.3 \%$ ) than that of capping material $(\approx 58.7 \%)$. However, the volume contraction of extrudates fired in the microwave furnace was significantly lower than that of extrudates fired conventionally at the same temperature. It should 
be noted that this observation may have been due to a shorter holding time of 30 minutes in the microwave furnace as compared to one hour and four hours respectively in the conventional furnace.

Weight loss in the firing of bauxite materials was mainly attributed to the decomposition of chemically bonded water, whereas volume contraction was primarily due to the mineralogical transformation and densification (Takeshita, et al., 1993). A significant increase of volume contraction occurred when the soaking time was prolonged. This indicated that mineralogical transformation resulted in densification of the extrudates.

The specific gravity of fired extrudates ranged between 2.97 and $3.51 \mathrm{~g} / \mathrm{cm}^{3}$, as indicated by Figures 7 and 8 . The change in the specific gravity is indicative of the relative proportions of the phases developed in the fired products. The specific gravity for the corundum, mullite, cristobalite and amorphous silica are 4.03, 3.03, 2.32 and $2.2 \mathrm{~g} / \mathrm{cm}^{3}$ respectively [Grimshaw, 1971]. The higher specific gravity of the fired beneficiated bauxite extrudates indicated that a higher proportion of corundum developed during the firing. This was verified by X-ray diffraction analysis.

\subsection{MINERALOGICAL DEVELOPMENT}

It was found that all the fired extrudates contained a small amount of cristobalite. The amounts of the corundum and mullite developed in the fired extrudates varied with the firing temperatures and the soaking time. The results are shown in the following figures and Table 3.

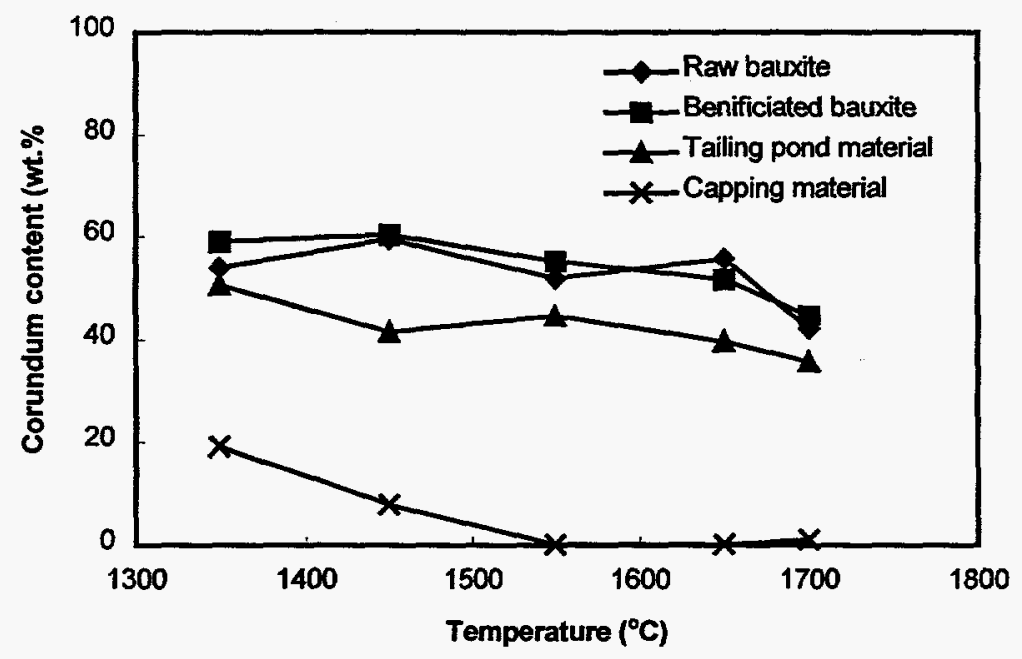

Figure 9. Corundum developed in the extrudates fired conventionally for one hour. 


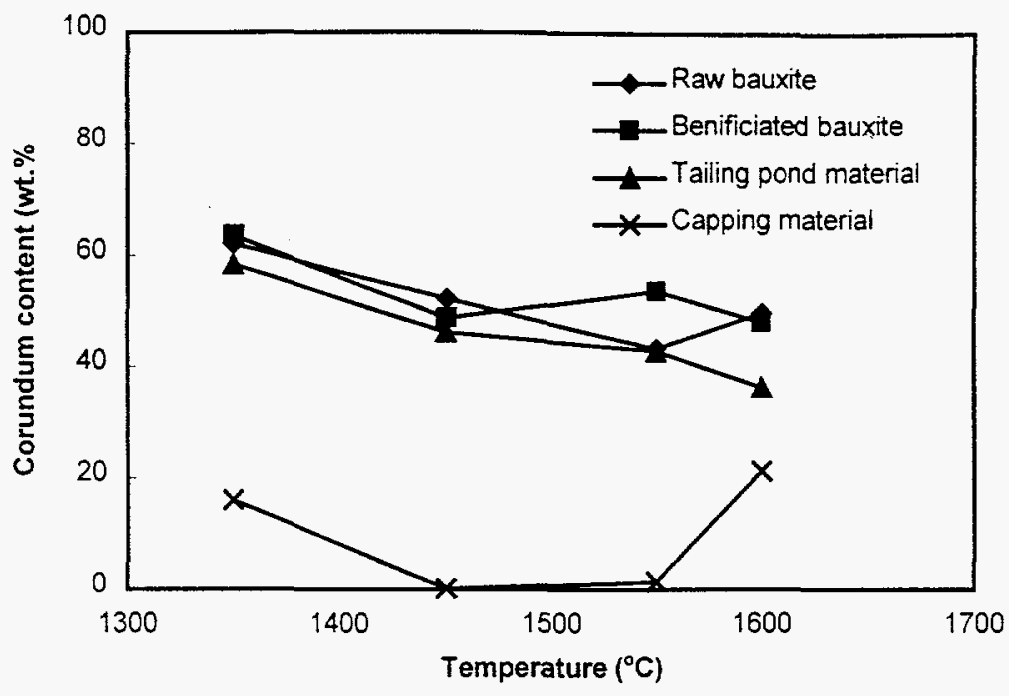

Figure 10. Corundum developed in the extrudates fired conventionally for four hours.

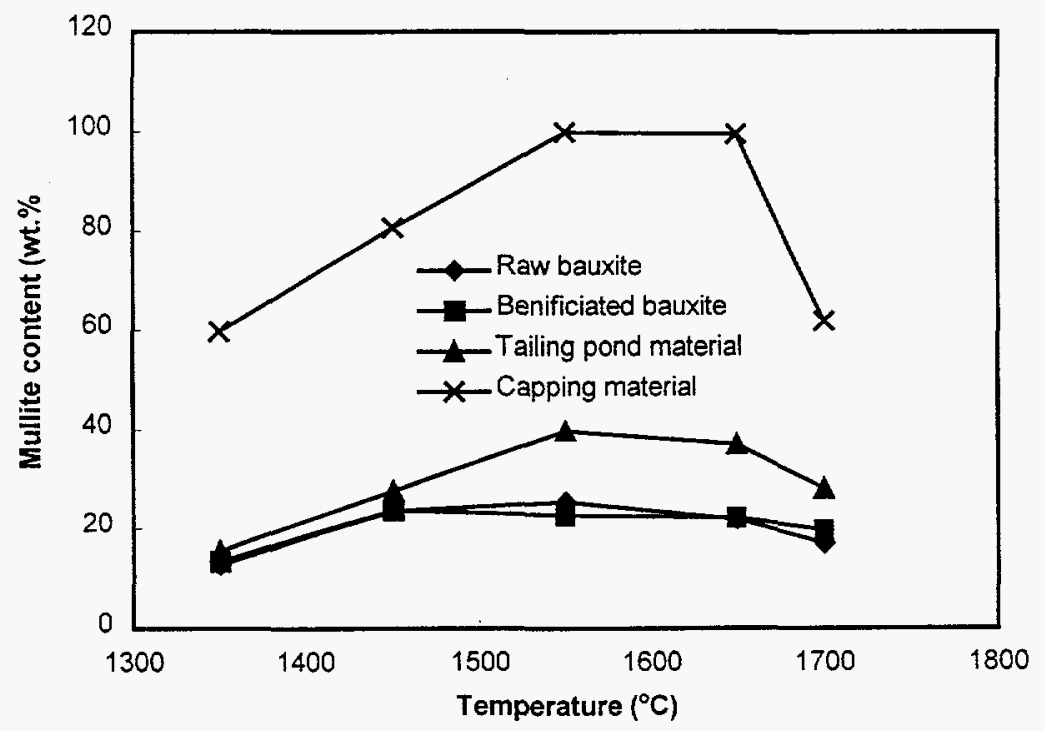

Figure 11. Mullite developed in the extrudates fired conventionally for one hour. 


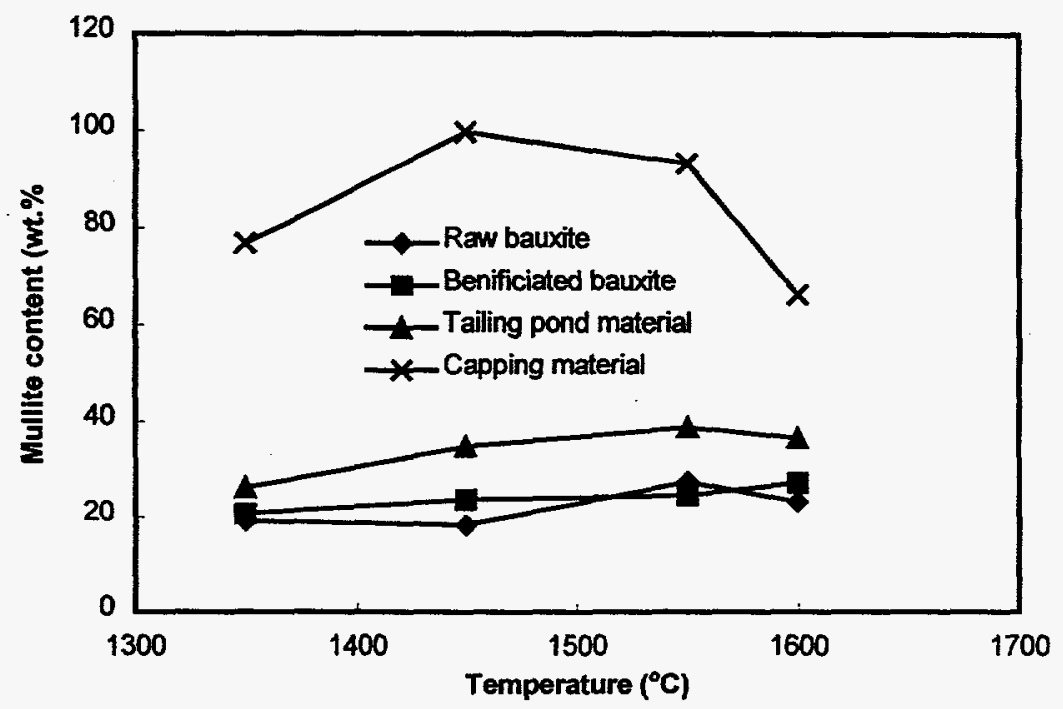

Figure 12. Mullite developed in the extrudates fired conventionally for four hours.

Table 3.

Mineralogical development in extrudates fired in a variable frequency microwave furnace (\%)

\begin{tabular}{|l|c|c|c|c|c|c|}
\hline & \multicolumn{3}{|c|}{ Corundum } & \multicolumn{3}{c|}{ Mullite } \\
\cline { 2 - 7 } & $1100^{\circ} \mathrm{C}$ & $1350^{\circ} \mathrm{C}$ & $1550^{\circ} \mathrm{C}$ & $1100^{\circ} \mathrm{C}$ & $1350^{\circ} \mathrm{C}$ & $1550^{\circ} \mathrm{C}$ \\
\hline Raw bauxite & 57.9 & 49.3 & 49.2 & 8.3 & 9.3 & 14.9 \\
\hline Beneficiated bauxite & 61.7 & 53.8 & 51.1 & 9.0 & 9.3 & 16.8 \\
\hline Tailing pond material & 59.1 & 50.8 & 39.7 & 12.2 & 19.4 & 19.1 \\
\hline Capping material & 25.3 & 12.8 & 1.6 & 34.5 & 53.8 & 65.8 \\
\hline
\end{tabular}

- Three firing regimes were: $1100^{\circ} \mathrm{C}$ for one minute, $1350^{\circ} \mathrm{C}$ for 30 minutes, and $1550^{\circ} \mathrm{C}$ for 30 minutes.

$\mathrm{X}$-ray diffraction analysis of the fired products revealed that gibbsite was completely converted to corundum in all extrudates. The predominant crystalline mineral phases in the fired extrudates were corundum and mullite. Only minor amounts of cristobalite were detected in all fired extrudates. This may be due to the fact that most of the silica had been consumed in the formation of mullite or existed as glassy phases which are not detectable by XRD.

As expected, the firing of beneficiated bauxite produced the highest content of corundum. At certain processing conditions, corundum development in capping material could be completely suppressed. For example, the higher content of corundum that was found in extrudates fired at $1100^{\circ} \mathrm{C}$ resulted from complete dehydration of gibbsite and a slower reaction rate for mullite formation. At $1350^{\circ} \mathrm{C}$, the higher rate of mullite formation from corundum and silica resulted in a lower corundum content. However, the highest mullite production occurred in the firing of capping material. Approximately $100 \%$ conversion to mullite occurred in the firing of capping material, whereas approximately $20 \mathrm{wt} \%$ mullite development occurred in the firing of 
beneficiated bauxite. The amount of mullite developed in microwave firing was comparable to that produced by conventional firing at the same temperature. However, a greater amount of mullite developed with increased soaking time when extrudates were fired conventionally in a high temperature furnace. The same result is anticipated with a microwave furnace.

\subsection{MICROWAVE EFFECT}

The results obtained from this investigation have indicated that at $1350^{\circ} \mathrm{C}$, the weight loss of extrudates fired conventionally was similar to that obtained in the microwave furnace. However, less volume contraction occurred in extrudates fired in the microwave furnace as compared to conventionally fired extrudates. There was no significant difference in the amount of corundum and mullite that developed in extrudates fired in each type of furnace, providing sufficient soaking time was allowed.

No significant difference in physical properties was detected in extrudates fired at the same temperature of $1350^{\circ} \mathrm{C}$ for 30 minutes in the microwave furnace, as compared with one hour in the conventional furnace. During microwave firing, the forward and reflected microwave power levels were measured using two directional couplers during the microwave firing. The electrical energy requirement was estimated by taking into consideration the efficiency of the microwave tube (travelling wave tube). The processing time and the electrical power requirement for these two batches are compared in Table 4 . The electrical power requirement for firing the extrudates in the microwave furnace during the ramp and soak periods was 1.2 and $0.8 \mathrm{KW}$ respectively, while that for the conventional furnace was 5.0 and $2.0 \mathrm{KW}$ respectively. It is clear from these results that the use of a microwave furnace would result in a significant saving in energy, as well as reduced processing time.

Table 4.

Processing time and electrical energy requirement for the microwave firing and conventional firing

\begin{tabular}{|l|c|c|c|c|c|c|}
\hline & \multicolumn{3}{|c|}{ Time (Minutes) } & \multicolumn{3}{c|}{ Electrical Energy (KWh) } \\
\hline & Ramp & Soak & Total & Ramp & Soak & Total \\
\hline Microwave & 20 & 30 & 50 & 0.4 & 0.4 & 0.8 \\
\hline Conventional & 270 & 60 & 330 & 22.5 & 2.0 & 24.5 \\
\hline
\end{tabular}

\subsection{DIELECTRIC CONSTANTS}

The dielectric constants of the materials vary with the temperature and were measured in-situ at three temperatures, as shown in Figures 13 through 16.

The dielectric properties of extrudates that were fired at temperatures of $500^{\circ} \mathrm{C}, 800^{\circ} \mathrm{C}, 1100^{\circ} \mathrm{C}$, $1350^{\circ} \mathrm{C}$ and $1600^{\circ} \mathrm{C}$ and allowed to cool to ambient conditions before measurement have been determined using an HP Network Analyzer with sample probe. The results are shown in Figures 17 through 20. 
The results of the measurement show that below $200^{\circ} \mathrm{C}$, the dielectric constant of each type of material is a function of the temperature and the microwave frequency. The values of the dielectric constants of the materials are around three. This indicates that these materials do not couple with the microwave field very well, thus hybrid heating method, using microwave susceptor to assist heating, has to be applied.

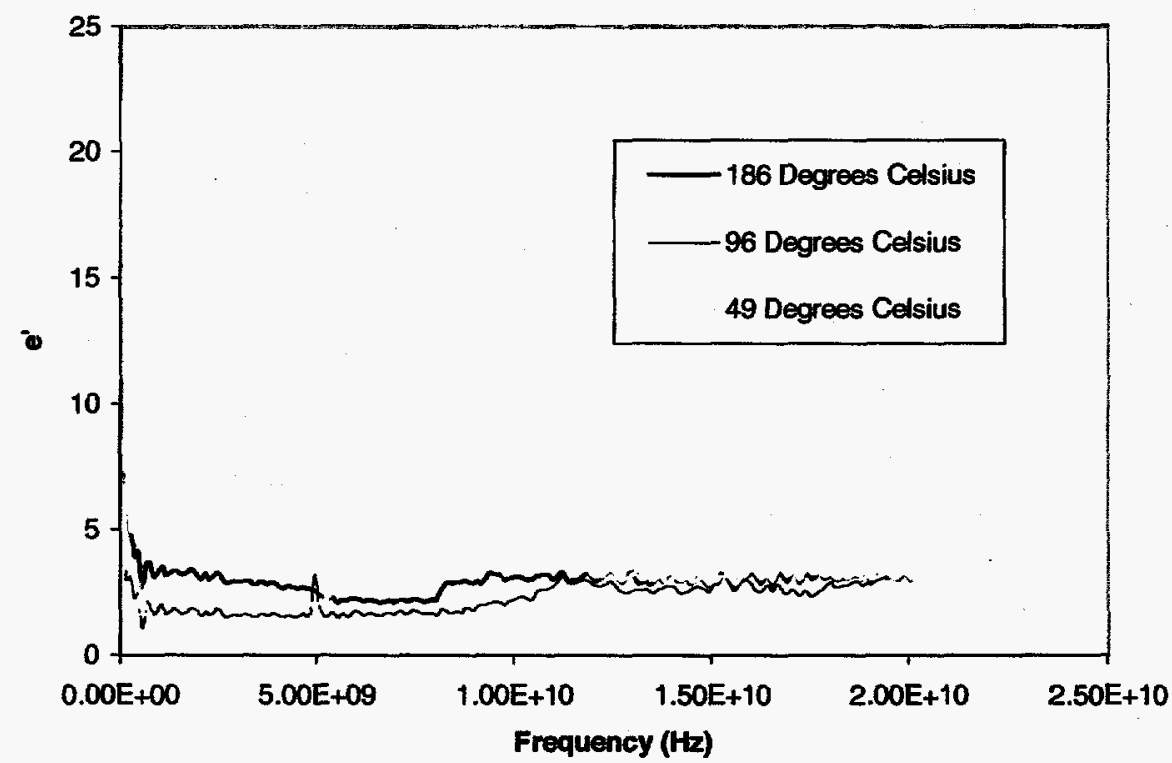

Figure 13. Dielectric constant of beneficiated bauxite at different temperatures.

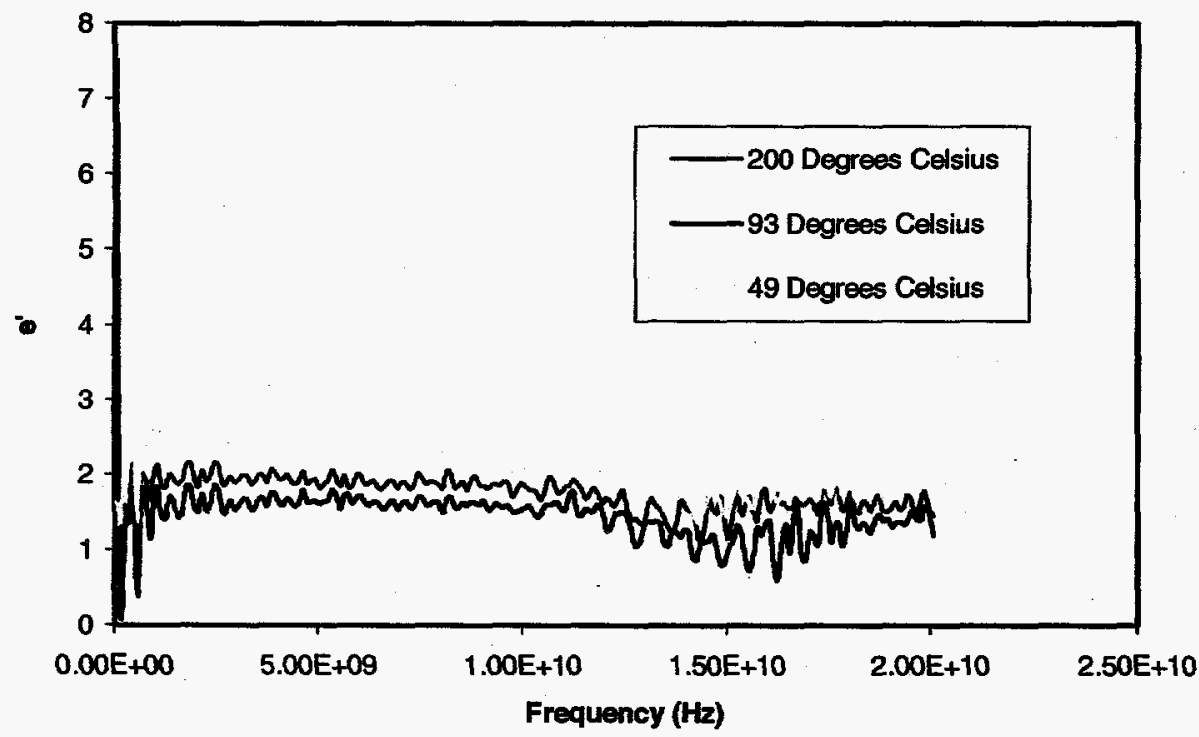

Figure 14. Dielectric constant of capping material at different temperatures. 


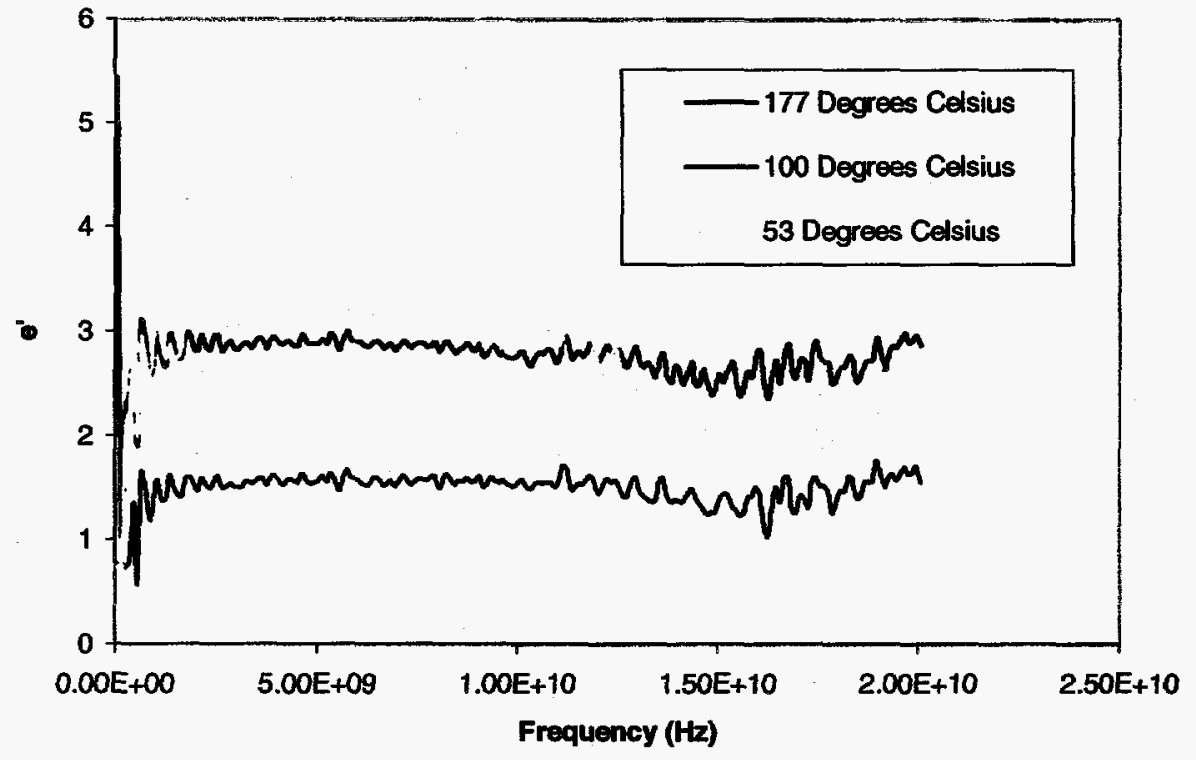

Figure 15. Dielectric constant of tailing pond material at different temperatures.

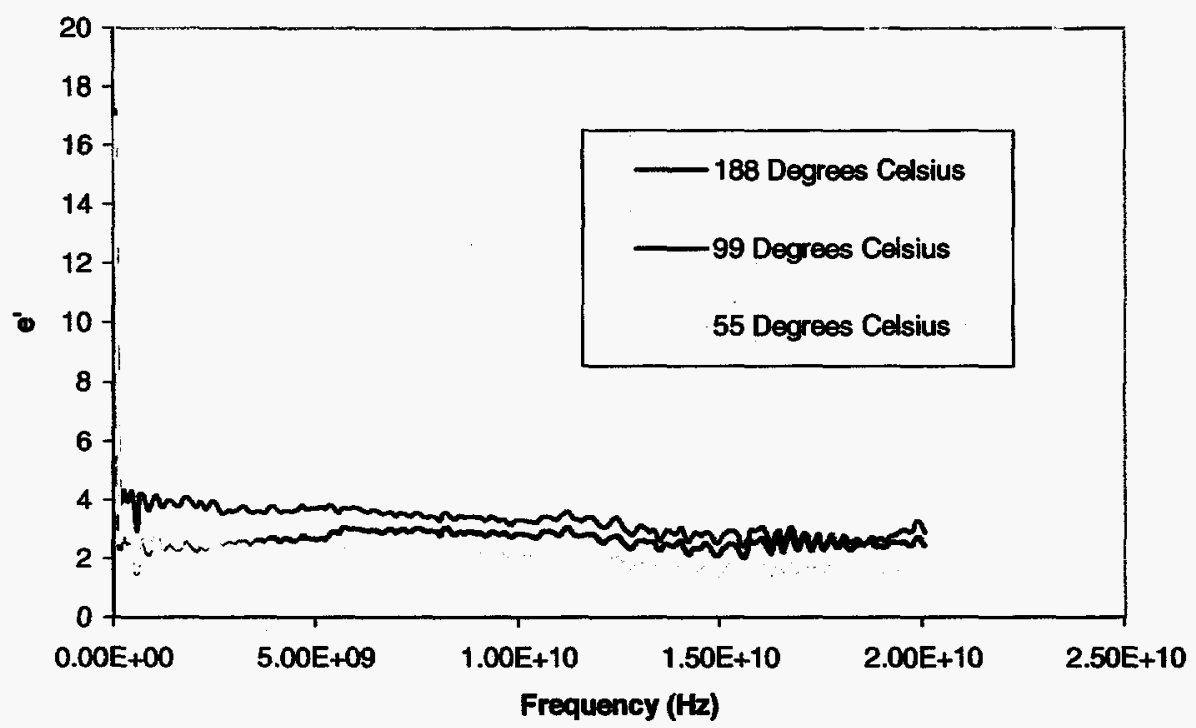

Figure 16. Dielectric constant of traditional bauxite at different temperatures. 


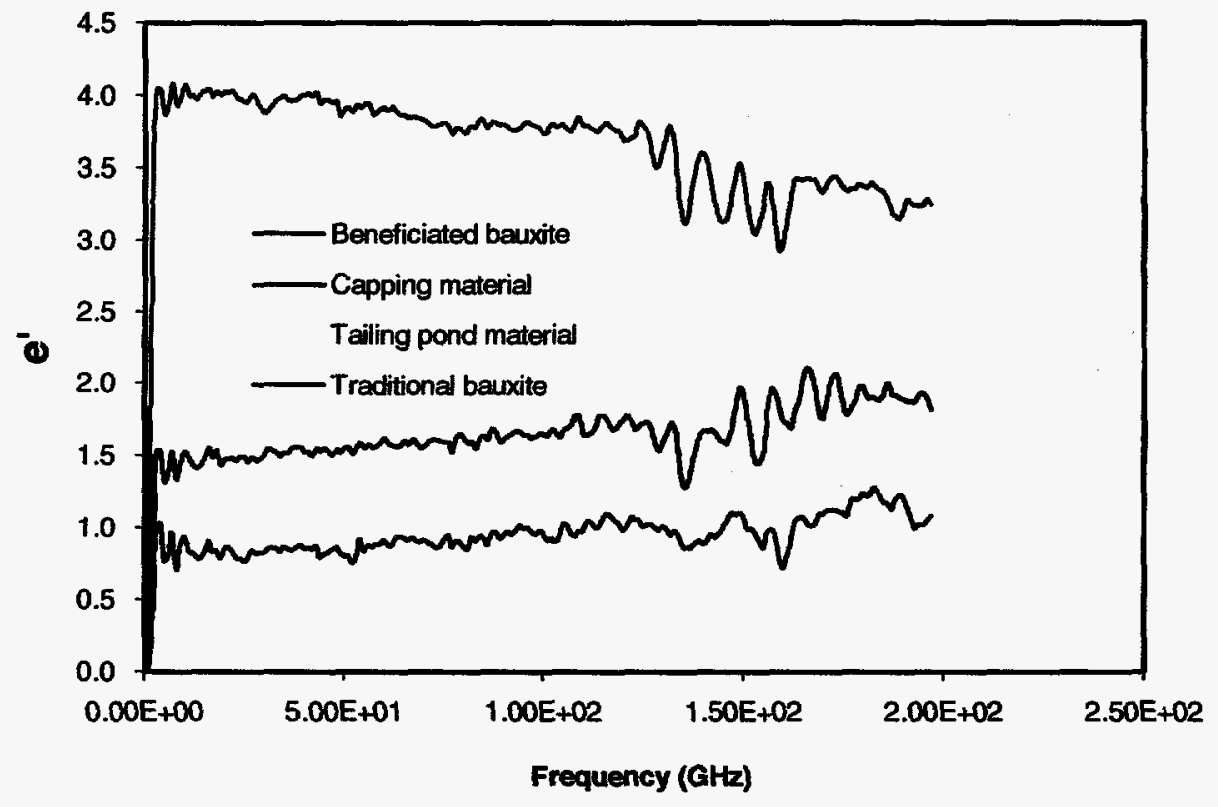

Figure 17. Dielectric constant of the product after fired at $500^{\circ} \mathrm{C}$.

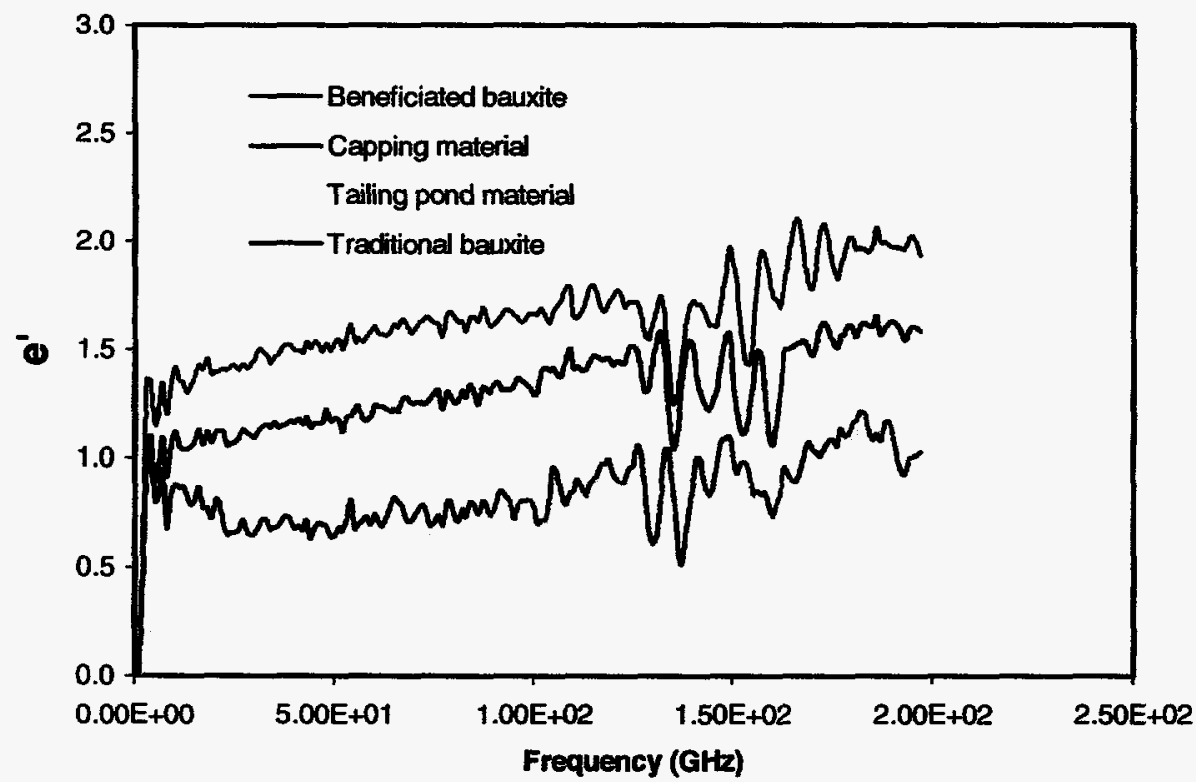

Figure 18. Dielectric constant of the products after fired at $1100^{\circ} \mathrm{C}$. 


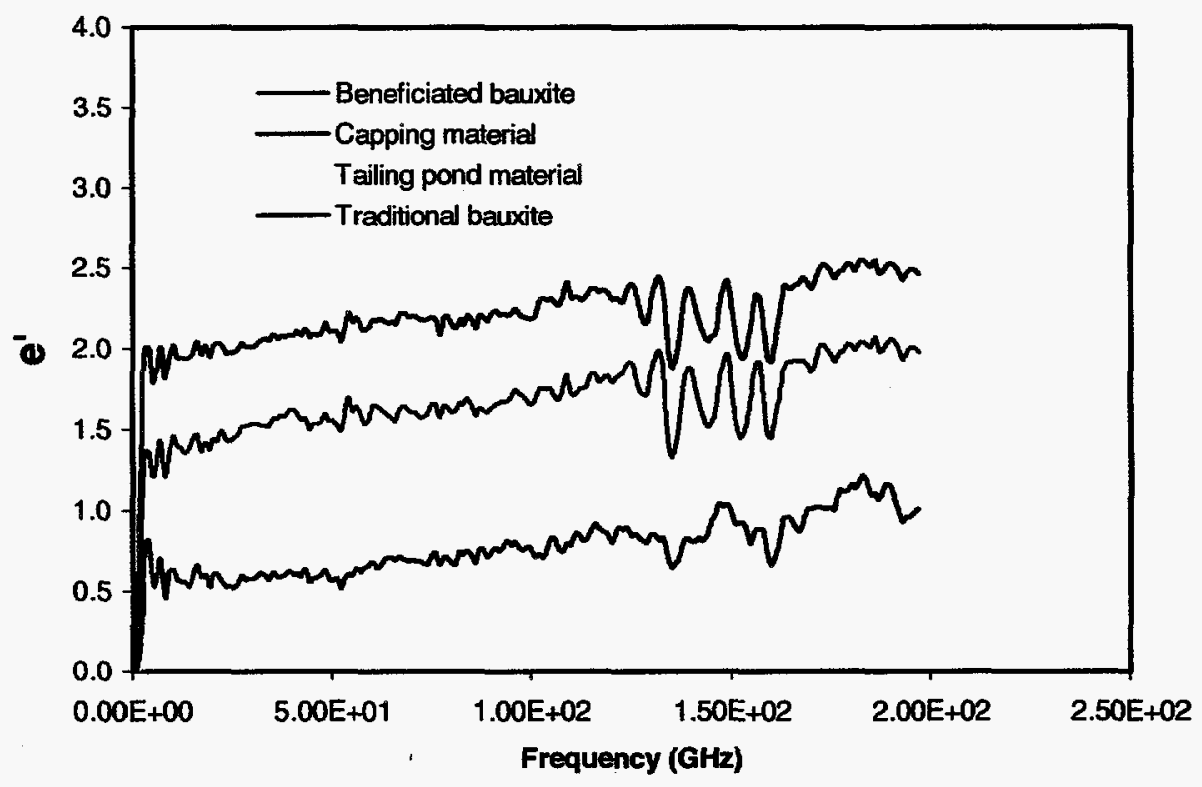

Figure 19. Dielectric constant of the products fired at $1350^{\circ} \mathrm{C}$.

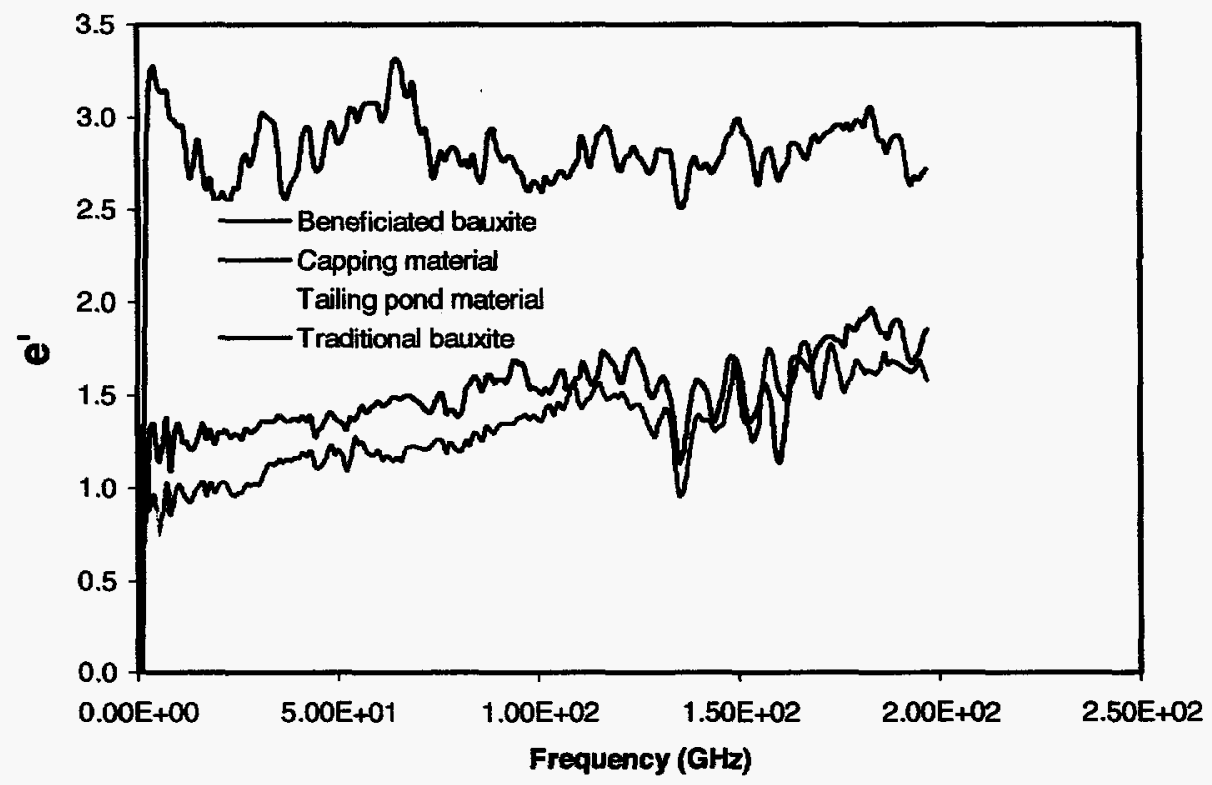

Figure 20. Dielectric constant of the products fired at $1600^{\circ} \mathrm{C}$. 


\subsection{MAJOR FY97 ACCOMPLISHMENTS}

- A $1.2 \mathrm{KW}$ variable frequency microwave furnace (VFMF) utilizing a frequency of 4.55 $4.75 \mathrm{GHz}$ has been used to fire alumino-silicate extrudates at $1100^{\circ} \mathrm{C}, 1350^{\circ} \mathrm{C}$ and $1550^{\circ} \mathrm{C}$ at Lambda Technologies, Inc. For comparison, extrudates were also fired in a graphite-lined furnace under helium and in a conventional high temperature furnace under an air atmosphere at a series of temperatures $\left(1350^{\circ} \mathrm{C}, 1450^{\circ} \mathrm{C}, 1550^{\circ} \mathrm{C}, 1600^{\circ} \mathrm{C}, 1650^{\circ} \mathrm{C}\right.$ and $1700^{\circ} \mathrm{C}$ ) for soaking periods of one hour and four hours respectively (November 1996 March 1997).

- Quantitative analyses of the mineralogical compositions, and the determination of physical properties such as weight loss, porosity, volume contraction and specific gravity of the fired products have been accomplished. These results show that the firing of ceramic materials in a microwave furnace can be successfully accomplished with a substantial saving in energy and processing time (April 1997 - May 1997).

- The dielectric constant of four types of alumino-silicate materials were measured in-situ at different temperatures ranging from approximately $40^{\circ} \mathrm{C}$ to $200^{\circ} \mathrm{C}$ and at various frequencies. The determination of the dielectric properties of extrudates ex-situ after firing the extrudates to temperatures of $500^{\circ} \mathrm{C}, 800^{\circ} \mathrm{C}, 1100^{\circ} \mathrm{C}, 1350^{\circ} \mathrm{C}$ and $1600^{\circ} \mathrm{C}$ and cooling to ambient conditions before measurement has also been accomplished (June 1997 - August 1997).

- Two technical papers have been published and presented at the following conferences: The 32nd Microwave Power Symposium (July 14-16, 1997 in Ottawa, Canada) and the Second International Congress on Metallurgy and Materials Technology (October 12-17, 1997 in Sao Paulo, Brazil). In addition, a refereed journal paper derived from this project has been accepted by the Journal of Microwave \& Electromagnetic Energy (June 1997 - October 1997). 
Day, P.S., D.J. Skamser, H.M. Jennings, D.L. Johnson, and M.S. Spotz, 1994, "Fabrication of $\mathrm{SiC}$ Matrix Surface Composites by Chemical Vapor Infiltration with Microwave Heating: Temperature Effects," Ceram. Eng. Sci. Proc., 15[5], pp. 908-15.

Deepak and J.W. Evans, 1993, "Mathematical Model for Chemical Vapor Infiltration in a Microwave-Heated Preform," J. Am. Ceram. Soc., 76[8], pp. 1924-29.

Devlin, D.J., R.P. Currier, R.S. Barbero, and B.F. Espinoza, 1993, "Chemical Vapor Infiltration with Microwave Heating," Ceram. Eng. Sci. Proc., 14[9-10], pp. 761-67.

Grimshaw, R.W. 1971. The Chemistry and Physics of Clays and Allied Ceramic Materials, 4th ed., Ernest Benn Limited, London, p. 712.

Munroe, N., A.M. Ebadian, and X. Tan, 1997, "Microwave Sintering and Combustion without Isostatic Pressure," Quarterly Report to DOE.

Ross, W.A., M.R. Elmore, C.L. Warner, L.J. Wachter, W.L. Carlson, and R.L. Devries, Proc. 18th Symp. on Waste Management, Tucson, AZ, March 1-5, Am. Nucl. Soc., pp. 112735.

Spotz, M.S., Skamser, D.J., Day, P.S., Jennings, H.M., and Johnson, D.L., 1993, "MicrowaveAssisted Chemical Vapor Infiltration," Ceram. Eng. Sci. Proc., 14[9-10], pp. 753-60.

Skamser, D.J., P.S. Day, H.M. Jennings, D.L. Johnson, and M.S. Spotz, 1994, "Hybrid Microwave-Assisted Chemical Vapor Infiltration of Alumina Fiber Compostes," Ceram. Eng. Sci. Proc., 15[5], pp. 916-23.

Takeshita, M., Matsuda, O., Watari, T. and Torikai, T. 1993. Sintering and mullite formation from kyanite-glass system, J. Ceram. Soc. Japan, Int. Edition, 101: pp. 1276-80.

Yin, Y., J. Binner, and T. Cross, 1997, "Microwave Assisted Chemical Vapor Infiltration for Ceramic Matrix Composites," in Microwaves: Theory and Application in Materials Processing IV, Ceramic Transactions, Vol. 80, D.E. Clark, W.H. Sutton and D.A. Lewis, eds., The American Ceramic Society, pp. 349-56. 